\title{
Use of healthcare resources, family function, and socioeconomic support during the first four years after preterm birth
}

\author{
I Leijon, O Finnström, G Sydsjö, M Wadsby
}

See end of article for authors' affiliations

\section{Correspondence to}

Associate Professor Leijon, Faculty of Health Sciences, Division of Paediatrics,

University Hospital, SE-58

85 Linköping, Sweden;

ingemar.leijon@imk.liu.se

Accepted

4 October 2002

\begin{abstract}
Objectives: To assess the use of healthcare resources for preterm infants and to evaluate family function and socioeconomic support in a defined population from birth to 4 years of age.

Methods: In a prospective case-control study, 39 singleton preterm infants without prenatal abnormalities born during an 18 month period were studied together with their families. The population consisted of 19 very preterm infants (less than 32 weeks) and 20 randomised moderate preterm infants (32-35 weeks), and the control group comprised 39 full term infants. Contacts with medical services, child health services, and the social welfare system were registered, and family function and life events were studied.

Results: The preterm children were more often readmitted to hospital (odds ratio (OR) 6.6, 95\% confidence interval (CI) 2.0 to 22.1 ) and had more outpatient attendances (OR 5.6, 95\% $\mathrm{Cl} 2.1$ to 15.0 ) during their first year of life. Mothers in the preterm group more often used temporary parental allowance than the control mothers $(p<0.001)$. The number of contacts with the child health services and the social welfare system did not differ significantly from the controls. Neither was there any significant difference with regard to family function or life events at 4 years of age.

Conclusions: A large proportion of the premature children used specialist care during the first years of life. However, the families of the preterm infants were socially well adapted up to four years after birth compared with the control families.
\end{abstract}

mprovements in routines and knowledge in neonatal care of preterm infants during recent decades have improved the survival rate and lowered the risk of disability among preterm and low birthweight infants. ${ }^{12}$ Long term health problems, including behavioural problems, are reported to be more common among children born prematurely, ${ }^{3-5}$ but little is known of the state of health of these infants with regard to the family situation. Preterm infants often remain in hospital for long periods because of neonatal complications, which leads to a high degree of parental stress, possibly with long term effects on the family. ${ }^{6}$ In the first years of life, these infants appear to use the health services more often than full term infants. $^{78}$

The aims of the study were to assess the use of healthcare resources in a cohort of children born prematurely compared with full term controls and to evaluate family function and socioeconomic support during the first 4 years of life for these groups.

\section{MATERIALS AND METHODS}

The children and their families lived in the central and western districts of the county of Östergötland with a population of 246 300. There are two obstetric departments in this area (the University Hospital in Linköping and the District Hospital in Motala), but the only paediatric department with neonatal care is located at the University Hospital, Linköping. During the study period, October 1993 to April 1995, 142 infants from this area were admitted to the neonatal intensive care unit. The study group contained preterm singelton infants without severe abnormalities who were born during the period. Those eligible for analysis were all infants born before 32 gestational weeks $(n=19)$ and a randomised sample of infants born between 32 and 35 weeks $(n=20)$ who fulfilled the inclusion criteria. Exclusion criteria were:
non-Swedish speaking parents; significant malformation detected before or after birth; infants with severe intrauterine growth retardation; twins. The children ( 24 boys and 15 girls) and their families were followed to the age of 4 years $( \pm 1$ month).

A control group $(n=39)$ was selected in the maternity wards. For each preterm infant, one full term infant, next in order to the index child of the same sex, was chosen in the obstetric department in which the preterm infant was born or would have been born if not referred. The same exclusion criteria were applied. One family in the control group was lost to follow up before the infant reached 4 years of age because they moved abroad.

\section{Maternal and neonatal data}

The following maternal information was collected neonatally: age, parity, and formal education (primary school 9 years, grammar school 2-3 years, or higher education). Every year until the infant reached 4 years of age, information on parental employment (full time work or reduced or part time) and the type of child day care was recorded through questionnaires. All mothers were cohabiting or married at the start of the study. The mothers of the very preterm infants and the mothers of the infants of 32-35 weeks gestation did not differ significantly with regard to age, parity, or level of education (table 1).

During the neonatal period, information was collected on gestational age, birth weight, intensive care treatment (ventilator/continuous positive airways pressure), number of

Abbreviations: $\mathrm{CHS}$, child health services; FARS, Family relation scale; $\mathrm{OR}$, odds ratio; $\mathrm{Cl}$, confidence interval; TPA, temporary parental allowance 
Table 1 Information on parents of the preterm infants and controls

\begin{tabular}{|c|c|c|c|c|}
\hline Variable & $\begin{array}{l}\text { Very preterm } \\
\text { children }(<32 \\
\text { weeks) }(n=19)\end{array}$ & $\begin{array}{l}\text { Moderately preterm } \\
\text { children }(32-35 \\
\text { weeks) }(n=20)\end{array}$ & $\begin{array}{l}\text { All preterm } \\
\text { children }(\leqslant 35 \\
\text { weeks) }(n=39)\end{array}$ & $\begin{array}{l}\text { Full term children } \\
(>36 \text { weeks }) \\
(n=39)\end{array}$ \\
\hline Age of mother (years) & $27.9(5.1)$ & $27.1(4.4)$ & $27.4(4.8)$ & $28.5(4.0)$ \\
\hline Primiparae $(\%)$ & 57.9 & 60.0 & 59.0 & 51.3 \\
\hline \multicolumn{5}{|l|}{ Education of mother } \\
\hline Primary school (\%) & 21.1 & 10 & 15.4 & 10.3 \\
\hline Grammar school (\%) & 36.8 & 70 & 53.8 & 48.7 \\
\hline Higher education (\%) & 42.1 & 20 & 30.8 & 41.0 \\
\hline \multicolumn{5}{|l|}{ Education of father } \\
\hline Primary school (\%) & 10.5 & 0 & 5.1 & 5.1 \\
\hline Grammar school (\%) & 68.4 & 70 & 69.2 & 66.7 \\
\hline Higher education (\%) & 21.1 & 30 & 25.6 & 28.2 \\
\hline
\end{tabular}

days in intensive care, total number of days in the neonatal ward, and type of feeding at discharge. The parents were allowed to spend as much time as they wanted with their infant in the neonatal ward. Infants who were ventilated or had serious complications during the neonatal period were followed by the neonatologist during the first year in accordance with the hospital's policy.

\section{Child assessments}

Health

After discharge, all infants attended the child health services (CHS), as do almost all children in Sweden. The recommended number of visits in the county of Östergötland was $13(0-1$ years), three ( $1-2$ years), and three ( $2-4$ years). For each child, the CHS nurse was asked to estimate the workload and number of visits up to 4 years of age. The workload was estimated according to a three grade scale: 1 , less than average; 2 , average; 3 , more than average. The standard preprinted CHS record was used for the evaluation. The estimates were made at 6 months, 12 months, 2 years, and 4 years of age. At 4 years of age, the CHS nurse applied the standardised tests of psychomotor development, speech ability, vision, and hearing according to the normal routine. ${ }^{9}$ A child was referred to a specialist if any deviations were detected. Readmissions to hospital, outpatient attendances, and general practitioner consultations were recorded by the parents through questionnaires. The parents used diaries to complete the questionnaires.

\section{Physical and neurological examination}

A general examination was performed at 4 years of age by one of the paediatricians in the study. The children were neurologically classified into five categories as described by Scheffzek et $a l^{10}: 0$, no noticeable deviation from normal; 1 , minor deviation; 2 , deviation requiring treatment; 3 , handicap; 4, severe multi-handicap.

\section{Behaviour}

The Richman behaviour screening questionnaire is for preschool children and was filled in by the parents just before the 4 year examination. It consists of 24 items designed to estimate difficulties in dealing with young children. Each behavioural item is rated 0,1 , or 2 points, with 0 signifying no or minor difficulties, and 2 signifying pronounced difficulties. Scores for all the items are summed to give a total, and a cut off point of 14 suggests that the child is at risk of developing behavioural problems. The items are also divided into three factors: hyperactive behaviour, isolation/immaturity, and anxiety. The questionnaire used has been modified and translated into Swedish ${ }^{11}$ from the original version. ${ }^{12}{ }^{13}$ Reliability (Cronbach's $\alpha$ ) and concurrent validity of the Swedish version of the instrument have been measured and found satisfactory.

\section{Family assessments}

Family relation scale (FARS)

This is a self reporting questionnaire consisting of 46 statements about family function. The statements can be either confirmed or denied by family members according to five alternatives: almost always, often, sometimes, seldom, and almost never. A total score was calculated, with a maximum of 86. A total score of 20 or more is regarded as high, indicating deviation from normal family function. This questionnaire is a modification of the American FACES schedule based on Olson's Circumplex model. ${ }^{14}$ FARS is a relatively new instrument with only slight similarities to FACES. After factor analysis, FARS also falls into five categories: attribution, interests, isolation, chaos, and enmeshment. ${ }^{15}$ The two questionnaires were mailed to the parents, who were asked to answer one questionnaire each separately. This was done by 38 of the mothers and fathers in the preterm group, and 34 mothers and fathers in the control group, when the child was 4 years old.

\section{Life events}

A form based on Coddington's ${ }^{16}$ original questionnaire and on Hurme's revised version for Scandinavia was used at 4 years of age. ${ }^{17}$ The form comprises 48 items (fig 1 ) focusing on changes in family composition and living conditions, child care, and parental occupation, illness and injury, death, emotional strains in the family, schooling, and peer relationships. Studies of life events and behavioural deviations during childhood have been conducted in Swedish populations, providing reference groups. ${ }^{17-19}$ A nurse trained for the purpose conducted the interview. Thirty eight of the parents in the preterm group and 35 in the control group were interviewed when the child was 4 years of age. The answers were carefully recorded by the nurse according to instructions given for conducting the interview

\section{Social support}

All Swedish residents earning at least 6000 SEK a year are covered by sick leave insurance. A person may be sick listed in two ways: with or without the support of a doctor's note. A doctor's note is required only when the period of sick leave exceeds seven days. Since 1995, parents are permitted 450 days of leave, 360 with $80 \%$ coverage of loss of income and 90 with standard compensation, which is the same for everyone. ${ }^{20}$ Both parents can enjoy this type of benefit by sharing the number of days available. Temporary parental allowance (TPA) is a benefit that one of the parents can use when the child is ill. The benefit is available until the child reaches 12 years of age. A maximum of 60 days a year is allowed.

The number of days of sick leave and TPA for both parents was obtained from the Regional Board of Social Insurance up 


\begin{tabular}{|c|c|}
\hline Family composition and living conditions & Death \\
\hline $\begin{array}{l}\text { 1. Birth or adoption of a brother or sister } \\
\text { 2. Addition of a third adult to the family } \\
\text { 3. Brother or sister leaving home } \\
\text { 4. Separation of parents } \\
\text { 5. Divorce of parents } \\
\text { 6. Family changes apartment/house } \\
\text { 7. Family moves to another address } \\
\text { 8. Jail sentence of parent } \\
\text { 9. Mother married to a step-parent } \\
\text { 10. Father married to a step-parent } \\
\text { 11. Discovery of being an adopted child } \\
\text { Child care and occupations of parents } \\
\text { 12. Beginning nursery school or daycare } \\
\text { 13. Change of nursery school or daycare } \\
\text { 14. Beginning pre-school year } \\
\text { 15. Mother beginning to work } \\
\text { 16. Father beginning to work } \\
\text { 17. Loss of job by parent } \\
\text { 18. Financial status of parents markedly reducd } \\
\text { 19. Parents' work requiring more absence from } \\
\text { home } \\
\text { Serious illness or injury } \\
\text { 20. Serious illness or injury of the mother } \\
\text { 21. Hospitalisation of the mother } \\
\text { 22. Serious illness or injury of the father } \\
\text { 23. Hospitalisation of the father } \\
\text { 24. Serious illness or injury of the child } \\
\text { 25. Hospitalisation of the child } \\
\text { 26. Hospitalisation of a brother or sister }\end{array}$ & $\begin{array}{l}\text { 27. Death of the mother } \\
\text { 28. Death of the father } \\
\text { 29. Death of a brother or sister } \\
\text { 30. Death of a grandparent } \\
\text { 31. Death of a close friend of the child } \\
\text { Schooling } \\
\text { 32. Beginning the } 1 \text { st year of education } \\
\text { 33. Change to a new school } \\
\text { 34. Failure of a year in school } \\
\text { 35. Beginning } 7 \text { th year of compulsory school } \\
\text { 36. Breaking up with a boy or girlfriend } \\
\text { 37. Menarche } \\
\text { 38. Unmarried pregnancy } \\
\text { 39. Fathering an unmarried pregnancy } \\
\text { 40. Abortion } \\
\text { Other events } \\
\text { 41. Having a congenital or acquired visible } \\
\text { handicap } \\
\text { 42. Decrease in arguments between parents } \\
\text { 43. Increase in arguments between parents } \\
\text { 44. Decrease in arguments with parents } \\
\text { 45. Increase in arguments with parents } \\
\text { 46. Outstanding personal achievement } \\
\text { 47. Change in child's acceptance by peers } \\
\text { 48. Other }\end{array}$ \\
\hline
\end{tabular}

Figure 1 A form based on Coddington' $\mathrm{s}^{16}$ original questionnaire and Hurme's revised version for Scandinavia designed to obtain information on life events. to the fourth birthday of the child. Data for one family in the control group were missing.

\section{Social welfare service}

After permission had been obtained from the parents, social welfare data were obtained from the records of the social welfare service of the study area. The data included whether the families had received financial support and/or support due to social circumstances, and/or had been the object of interventions due to social problems. Data were obtained for 37 of the families in the preterm group and 34 families in the control group. For three families, no information was available from the records because the head of the local social welfare service did not give his approval. According to the parents themselves, no contact had taken place.

\section{Statistical methods}

Odds ratios (OR), with 95\% confidence intervals (CI), were used to analyse the differences between the cases and the references. OR was estimated by using the logistic regression analysis procedure in the SPSS program package.

For (approximately) normally distributed continuous variables, the differences between the two groups (cases $v$ references) were tested with the $t$ test. The Mann-Whitney $\mathrm{U}$ test was used when the assumptions of the asymptotic method could not be met.

\section{Ethics}

The study was approved by the ethics committee of the Faculty of Health Sciences, University of Linköping.

\section{RESULTS}

\section{Health of the child}

The mean gestational age (weeks) and birth weight ( $\mathrm{g}$ ) of the preterm infants were 31.1 (95\% CI 30.1 to 32.1 ) and 1740
(95\% CI 1551 to 1930 ) respectively. Twenty one $(54 \%)$ of the preterm infants and none of the controls were born by caesarean section. Seven of the preterm infants were treated with a ventilator, and nine with continuous positive airways pressure only. The median duration of intensive care was 4.5 days, and the median total stay in the neonatal ward was 42.0 days. At discharge from the neonatal or maternity ward, 29/38 (76\%) of the preterm infants and $36 / 39(92 \%)$ of the control infants were being breast fed (OR 3.72; 95\% CI 0.92 to 15.03).

Four preterm children had mild cerebral palsy, one with hydrocephalus. A third $(34 \% ; 13 / 38)$ of the preterm group and $2 / 35(6 \%)$ of the control group were in Scheffzek categories 1-2 (OR 8.58; 95\% CI 6.04 to 12.19). There were no handicapped children (categories 3 or 4 ).

There were no significant differences between the groups according to the Richman behaviour screening questionnaire (table 2). Three preterm children with hyperactivity scored outside the normal range $(\geqslant 14)$, indicating behavioural problems (OR 1.97; 95\% CI 1.56 to 2.49 ).

The estimation by the CHS nurse of workload did not differ significantly between the groups (data not shown). The preterm infants visited the CHS slightly more often than the controls (table 3). The percentage of premature children who had visited a general practitioner was similar to the controls up to 4 years of age. During the first 4 years of life, a higher percentage of premature children visited a specialist (table 3 ). A third $(13 / 39 ; 33 \%)$ of the preterm group and $4 / 38(11 \%)$ of the controls were referred to a specialist after routine examination by the CHS nurse at 4 years of age (OR 4.42; $95 \%$ CI 3.13 to 6.24). Readmission to hospital occurred at a rate of $17 / 39(44 \%)$ for preterm children and 4/38 (11\%) for controls before 1 year of age (OR 6.57; 95\% CI 1.95 to 22.12) and 8/39 $(21 \%)$ for preterm children and $5 / 38(13 \%)$ for controls between 1 and 4 years of age (OR 1.70; $95 \%$ CI 0.50 to 5.77 ). 


\begin{tabular}{|c|c|c|c|}
\hline Variable & $\begin{array}{l}\text { Preterm } \\
(n=38)\end{array}$ & $\begin{array}{l}\text { Full term } \\
(n=34)\end{array}$ & p Value* \\
\hline Out acting & $3.68(2.23)$ & $3.32(1.68)$ & 0.635 \\
\hline Isolated/immature & $0.89(1.13)$ & $0.74(0.99)$ & 0.624 \\
\hline Anxious & $2.37(2.10)$ & 2.38 (1.54) & 0.566 \\
\hline Total points & $6.95(4.11)$ & $6.44(2.60)$ & 0.910 \\
\hline \multicolumn{4}{|l|}{$\begin{array}{l}\text { Odds ratio of total } \\
\text { points }\end{array}$} \\
\hline$<14$ points & 35 & 34 & $\begin{array}{l}\text { Reference } \\
\text { category }\end{array}$ \\
\hline$\geqslant 14$ points & 3 & 0 & $\begin{array}{l}1.97 \\
(1.56 \text { to } 2.49)\end{array}$ \\
\hline
\end{tabular}

Values are mean (SD).

*Based on the Mann-Whitney U test.

\section{Family dato}

During pregnancy, 59\% of the mothers in the preterm group and $38.5 \%$ of the control mothers were sick listed with a doctor's certificate. The most common diagnosis in both groups was back pain. The number of days of sick leave did not differ significantly between the preterm and full term groups during the first 4 years of life. The preterm mothers used significantly more days of TPA $(p<0.001)$. The fathers' use of TPA did not differ between the groups. Table 4 presents the median number and range of days of those parents who were sick listed or used the TPA.

The parents of the premature children did not differ significantly from the controls with regard to working conditions outside the home (data not shown). The percentages of preterm children and controls attending day care centres at 4 years of age were similar (56\% (20/36) and 57\% (20/35) respectively).

The FARS showed no significant differences between the families (table 5). This was true for the total score as well as the five category scores. The number of families functioning
Table 4 Parental sick leave insurance (SLI) and the use of temporary parental allowance (TPA) during the child's first four years of life

\begin{tabular}{llll}
\hline Variable & $\begin{array}{l}\text { Preterm } \\
(\mathrm{n}=39)\end{array}$ & $\begin{array}{l}\text { Full term } \\
(\mathrm{n}=37)\end{array}$ & $\mathrm{p}$ Value* \\
\hline $\begin{array}{l}\text { SLI, mother (days) } \\
\text { Median (range) } \dagger\end{array}$ & $\begin{array}{l}45.0(60.5) \\
27.0(1-264)\end{array}$ & $\begin{array}{l}34.0(53.5) \\
12.5(2-223)\end{array}$ & 0.200 \\
& & & \\
SLI, father (days) & $82.9(310.9)$ & $16.3(31.9)$ & 0.481 \\
Median (range)† & $22.0(1-1432)$ & $11.5(0.5-174)$ & \\
& & & \\
TPA, mother (days) & $39.1(36.6)$ & $10.8(9.6)$ & $<0.001$ \\
Median (range) $\dagger$ & $35.3(5-206)$ & $11.0(2-45)$ & \\
& & & \\
TPA, father (days) & $13.1(19.5)$ & $6.4(9.8)$ & 0.124 \\
Median (range) $\dagger$ & $11.0(0.5-87)$ & $5.5(1-38)$ & \\
\hline
\end{tabular}

Values are mean (SD).

*Mann-Whitney U test.

†Median and range for those who were sick listed or used the TPA.

Table 5 Family function according to the Family relation scale (FARS), with odds ratio (OR) and $95 \%$ confidence interval $(\mathrm{Cl})$ for the cut off of 20

\begin{tabular}{|c|c|c|c|}
\hline Variable & $\begin{array}{l}\text { Preterm } \\
(n=38)\end{array}$ & $\begin{array}{l}\text { Full term } \\
(n=34)\end{array}$ & OR $(95 \% \mathrm{CI})$ \\
\hline \multicolumn{4}{|c|}{ FARS, mother } \\
\hline$\leqslant 20$ & 34 & 32 & Reference category \\
\hline$>20$ & 4 & 2 & $1.94(0.33$ to 11.34$)$ \\
\hline \multicolumn{4}{|c|}{ FARS, father } \\
\hline$\leqslant 20$ & 32 & 31 & Reference category \\
\hline$>20$ & 6 & 3 & $1.94(0.45$ to 8.44$)$ \\
\hline
\end{tabular}

outside the normal range did not differ significantly between the groups.

Irrespective of whether the children were born preterm or at term, the groups experienced the same number of life events

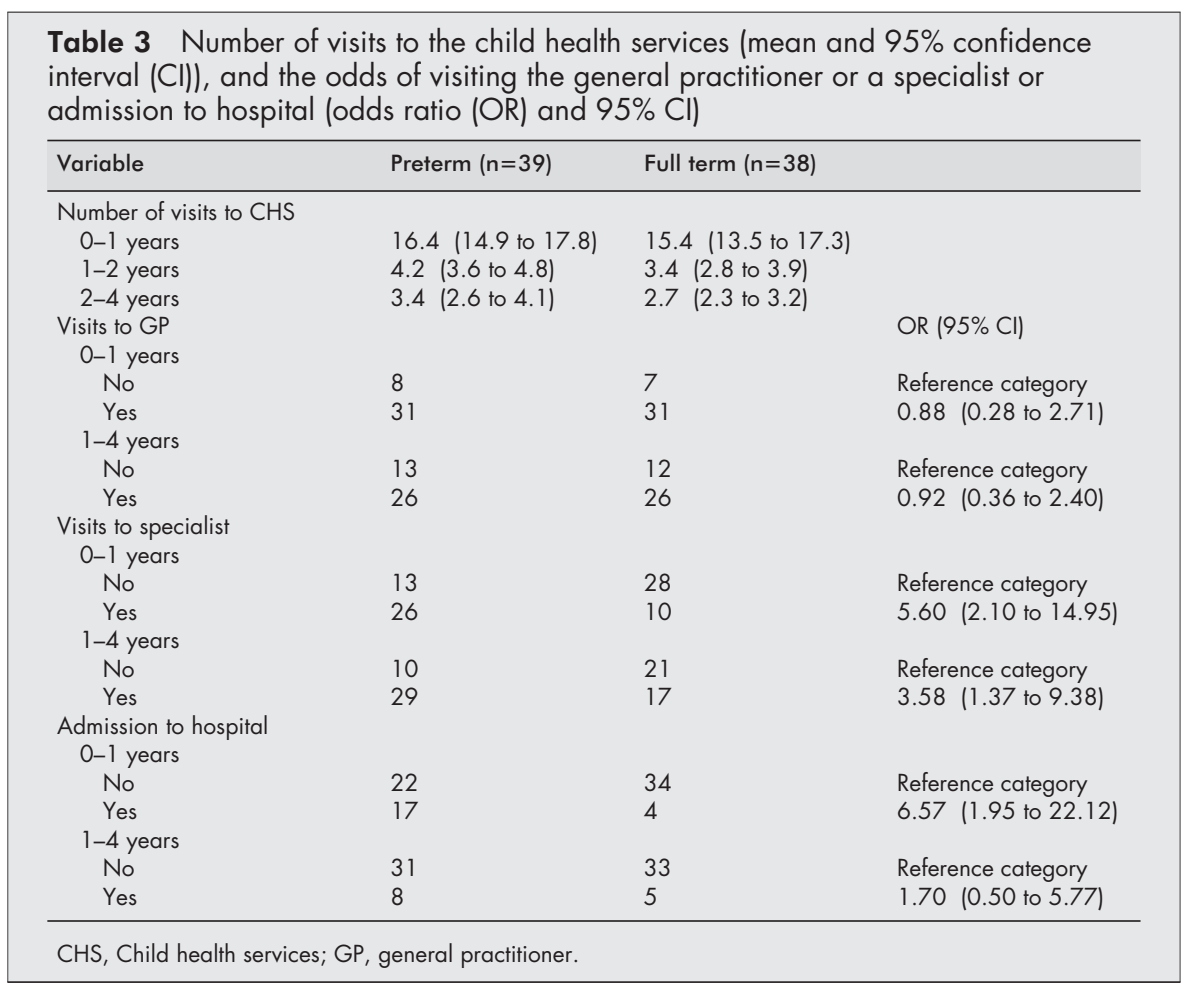


Table 6 Occurrence of life events during the first 4 years of life

\begin{tabular}{llll}
\hline Variable & Preterm $(n=38)$ & Full term $(n=35)$ & $p$ Value* \\
\hline No of life events & $5.3(2.4)$ & $4.4(2.3)$ & 0.0927 \\
No of life events experienced as negative & $0.7(0.9)$ & $0.6(0.9)$ & 0.7385 \\
No of life events experienced as difficult to adjust to & $0.7(0.9)$ & $0.7(1.0)$ & 0.9898 \\
\hline $\begin{array}{l}\text { Values are mean (SD). } \\
\text { *Mann-Whitney U test. }\end{array}$ & & & \\
\end{tabular}

(table 6). The most common during the first 4 years of life were birth of a sibling, moving house, starting nursery school or day care, and mother starting work. Of these events, it was the birth of a sibling that was scored as the most difficult event to adjust to for the children.

Seventy one (90\%) families were studied with regard to contacts with the social services. Two of the families in each group were found to have had contact, in both cases for financial support.

\section{DISCUSSION}

This prospective study comprised preterm infants born within a defined geographical area with a population mix probably representative of the country. The control children were matched for date of birth, place of birth, and sex in order to minimise social differences between the groups. Immigrant parents without a good knowledge of Swedish were excluded because part of the study was based on parental inquiries. Of the social factors important for the children's wellbeing, we chose maternal age, parity, and the parents' formal school education, but found no significant differences between the groups. Within the preterm group, there were no significant differences with regard to these factors between mothers with infants born before 32 weeks and mothers with infants born between 32 and 35 weeks, and the categories were therefore combined. We excluded twins and infants with severe congenital malformations or severe growth retardation in order to study preterm infants and families without major medical factors other than those associated with prematurity.

The preterm infants were treated according to the routines of the neonatal ward, and their parents received conventional support, which was relatively extensive. The staff did not know that the infant and family were enrolled in the study. During the follow up period up to 4 years of age, the children and parents received traditional monitoring and treatment by the CHS, hospital clinics, or rehabilitation centre, if needed. Therefore the groups represent infants and families covered by conventional health services.

In comparison with the controls, a larger number of premature infants had been readmitted to hospital during the first year of life, as previously reported. ${ }^{37}$ The more common occurrence of sickness was reflected in the more extensive use of the TPA by the preterm mothers. A larger number of preterm infants saw specialists during the first year of life, which may partly be explained by the hospital follow up programme of certain very preterm infants with neonatal complications. Children with serious neurofunctional problems and their families were cared for by the rehabilitation centres, providing the parents with information and support. In addition to the follow up programme and rehabilitation activities, all children attended the CHS, as do almost all Swedish children. These factors probably explain why there were no differences in the number of visits to the CHS and the workload of the CHS nurse.

We described neurological function using the classification of Scheffzek et al ${ }^{10}$ because it is simple to apply and provides distinct categories. We found no handicapped children but a larger number of premature children with neurofunctional dysfunction, which we also observed in a previous study. ${ }^{21}$ The grade of disability was minor; otherwise, the stress experienced by the families would probably have been greater. To evaluate behavioural factors that could affect family function, we also used the Richman behavioural screening questionnaire. There were no significant differences between the groups, but a higher rate of hyperactive behaviour was found, which has previously been reported in very low birthweight children. ${ }^{22-24}$ It did not seem to lead to a higher risk of family dysfunction.

The method of estimating level of family functioning (FARS) has shown satisfactory results with regard to measures of reliability (internal consistency and stability over a long period) and validity - that is, correlation with mental health status in children and in comparison with other measures of family functioning. ${ }^{15}$ Stjernqvist ${ }^{25}$ stated that, at a four year follow up of extremely preterm children, there were no significant differences in effect on the stress level of families compared with controls consisting of families with full term children. This is in agreement with our results, which comprised preterm children with a higher gestational age. Children at psychosocial risk are found to have a larger number of negative life events than children not at risk. ${ }^{196}$ However, no differences in the number of life events were found between our groups. According to the social welfare records, no child had been subjected to an investigation of offense. A larger study group may have produced a different result. Another explanation may be that the Swedish medical and social welfare system is fairly well developed, providing the opportunity to support parents at risk. It seems that the families with preterm infants were, in general, socially well adapted.

To conclude, preterm children have more health problems and require more medical care and maternal social benefits than full term children, at least during the first year of life. In spite of this, the families seem to cope with their lives and social situation as well as controls. Thus, families in Sweden with a premature child free of serious prenatal malformation or severe growth retardation appear to be socially well adapted by the time the child reaches 4 years of age.

\section{ACKNOWLEDGEMENTS}

This study was supported by grants from the County of Östergötland, the Mayflower Annual Campaign, and the Sven Jerring Foundation. We thank Dr Göran Hermansson for his cooperation, Katarina Ekholm for statistical advice, and registered nurse Christine Rosén for excellent help in communication with the families.

\section{Authors' affiliations}

I Leiion, O Finnström, Faculty of Health Sciences, Division of Paediatrics, University Hospital, Linköping, Sweden

G Sydsiö, Division of Obstetrics and Gynaecology, University Hospital, Linköping

M Wadsby, Division of Child and Adolescent Psychiatry, University Hospital, Linköping

\section{REFERENCES}

1 Finnström O, Otterblad P, Olausson P, et al. Neurosensory outcome and growth at three years in extremely low birth-weight infants: follow-up results from the Swedish national prospective study. Acta Paediatr 1998:87: 1055-60. 
2 Grögaard JB, Lindström DP, Parker RA, et al. Increased survival rate in very low birth weight infants (1500 grams or less): no association with increased incidence of handicaps. J Pediatr 1990;1 17:139-46.

3 Hack $M$, Weissman B, Breslau N, et al. Health of very low birth weight children during their first eight years. J Pediatr 1993;1 22:887-92.

4 Stjernqvist K, Svenningsen NW. Ten-year follow-up of children born before 29 gestational weeks: health, cognitive development, behaviour and school achievement. Acta Paediatr 1999;88:557-62.

5 Yuksel B, Greenough A. Birth weight and hospital readmission of infants born prematurely. Arch Pediatr Adolesc Med 1994;148:384-8.

6 Stjernqvist KM. Extremely low birth weight infants less than $901 \mathrm{~g}$. Impact on the family during the first year. Scand J Soc Med 1992;20:226-33.

7 van Zeben-van der Aa DM, Verloove-Vanhorick SP, Brand R, et al. The use of health services in the first 2 years of life in a nationwide cohort of very preterm and/or very low birth-weight infants in The Netherlands: rehospitalisation and out-patient care. Paediatr Perinat Epidemiol 1991;5:11-26

8 Jackson K, Schollin J, Bodin L, et al. Utilization of healthcare by very-low-birth-weight infants during their first year of life. Acta Paediatr $2001 \cdot 90 \cdot 213-17$

9 Köhler L. Health control of four-year-old children. An epidemiological study of child health. Acta Paediatr Scand 1973;235(suppl): 1-28.

10 Scheffzek A, Stahl M, Toenges V. Die prognose der sehr kleinen Frugeburt. Katamnestische Untersuchungen an fruhgeborenen bis zu einem Geburtsgewicht von 1000 gramm. Monatsschr Kinderheilkd $1989 ; 137: 42-8$

11 Gustafsson P, Höök B, Larsson IB. Richman: an instrument for screening behaviour disturbances among preschool children. Linköping: Division of Child and Adolescent Psychiatry, 1993:No 14

12 Richman N, Graham P. A behaviour screening questionnaire for use with three year old children. J Child Psychol Psychiatry 1971;12:5-33.

13 McGuire J, Richman N. The prevalence of behavioural problems in three types of preschool group. J Child Psychol Psychiatry 1986;27:455-72.

14 Olson DH. Circumplex model VII: validation studies and FACES III. Family Process 1986;25:337-51.
15 Höök B, Cederblad M. Family relation scale (FARS): a self-reporting questionnaire measuring family function. Lund: Department of Child and Adolescent Psychiatry, 1992; No 1

16 Coddington RD. The significance of life events as etiologic factors in the diseases of children. II. A study of normal population. J Psychosom Res 1997:16:205-13.

17 Hägglöf B, Blom L, Dahlquist G, et al. The Swedish childhood diabetes study: indications of severe psychological stress as a risk factor for Type 1 (insulin-dependent) diabetes mellitus in childhood. Diabetologica $1991 ; 34: 579-83$

18 Höök B, Hägglöf B, Thernlund G. Life events and behavioural deviations in childhood: a longitudinal study of a normal population. Eur Child Adolesc Psychiatry 1995;4:153-64

19 Wadsby M, Sydsjö G, Svedin CG. Children of psychosocial risk-mothers: life events, social interaction and behaviour problems at the age of 8 years. Scand J Soc Med 1996;24:227-36.

20 National Social Insurance Board, RFV. Social insurance expenditure. Stockholm: National Social Insurance Board, 2000.

21 Bylund B, Cervin T, Finnstrom O, et al. Morbidity and neurological function of very low birth-weight infants from the newborn period to $4 \mathrm{y}$ of age. A prospective study from the south-east region of Sweden. Acta Paediatr 1998;87:758-63.

22 Bylund B, Cervin T, Finnström $O$, et al. Very low birth weight children at 9 years: school performance and behaviour in relation to risk factors. Prenatal and Neonatal Medicine 2000;5:124-33.

23 Scothorst PE, van Engeland $\mathrm{H}$. Long-term behavioral sequelae of prematurity. J Am Acad Child Adolesc Psychiatry 1996;35:175-83.

24 Sommerfelt K, Troland K, Ellertsen B, et al. Behavioural problems in ow-birth-weight preschoolers. Dev Med Child Neurol 1996:38:927406.

25 Stjernqvist K. Extremely low birth weight infants. Development behaviour and impact on the family. PhD dissertation, University of Lund, 1992.

26 Sydsiö G. Prevalence and significance of social and psychological risk factors during pregnancy. Int J Technol Assess Health Care 1992;8(supp 1):123-8. 